\title{
Protección de los acreedores, intercambio de información y crédito para pequeñas y medianas empresas: datos comparativos entre países
}

\author{
Arturo Galindo y Alejandro Micco
}

\section{Resumen}

Utilizando la Encuesta mundial sobre el ambiente de los negocios (World Business Environment Survey o WBES) para empresas en 61 países y variables ficticias que permiten abordar los componentes específicos, observados y no observados, de cada uno de ellos, así como una endogeneidad parcial, se analiza el papel de la protección de los acreedores (por ejemplo, la ejecución de contratos de crédito) y del desarrollo de mecanismos de información crediticia (como los registros de préstamo) en la determinación de la disponibilidad de financiación bancaria para pequeñas y medianas empresas (pymes). Se encuentra que una mejor protección de los acreedores y el desarrollo de mecanismos de intercambio de información reducen la brecha de financiamiento existente entre las pequeñas y las grandes empresas. Los países con un bajo nivel de protección de los acreedores pueden compensar esta falencia mediante la implementación de mecanismos de información crediticia.

Palabras clave

Pequeñas empresas, empresas medianas, financiamiento de empresas, crédito, controles de crédito, acceso a la información, modelos econométricos

Clasificación JEL

G30, G10, K40

Autores

Alejandro Micco es Subsecretario del Ministerio de Hacienda de Chile. alejandro.micco@ gmail.com

Arturo Galindo es Jefe de la División de Desarrollo Estratégico del Banco Interamericano de Desarrollo. agalindo@iadb.org 


\section{Introducción}

Existe una vasta literatura en la que se destaca la influencia positiva del desarrollo del sector financiero de un país sobre el nivel y la tasa de crecimiento del ingreso per cápita. El crédito proporcionado por el sector bancario es la fuente de financiamiento más importante para las empresas y los hogares en la mayoría de los países, sobre todo en los países en desarrollo. Desafortunadamente, el crédito bancario es más costoso y más limitado para las pymes que para las grandes empresas, que además disponen de una mayor oferta de opciones financieras. Mediante el uso de datos de sección transversal comparables sobre el crédito bancario comercial en 61 países, ajustando por efectos fijos del país, analizamos la importancia de: i) el papel del sistema jurídico al requerir y ejecutar el pago del préstamo y la superioridad del régimen de derecho común a este respecto, y ii) los distintos tipos de protección institucional, como los organismos de información crediticia, que pueden corregir las asimetrías de información que desalientan a los prestamistas, y su papel a la hora de determinar el acceso al crédito bancario. Constatamos que el porcentaje de financiamiento total que se obtiene de los bancos es alrededor de 30 puntos porcentuales más alto en el caso de las pymes en países con regímenes de derecho común que en aquellos con sistemas de tradición romanista. La existencia de un registro de crédito también aumenta alrededor de 30 puntos porcentuales el nivel de crédito bancario para pymes en relación con las grandes empresas. Asimismo, nuestros resultados revelan que los derechos de los acreedores y la existencia de un registro de crédito son sustitutos el uno del otro. En consecuencia, los registros de crédito tienen un fuerte impacto sobre el crédito en países con bajos niveles de protección jurídica (véase el cuadro 3).

En los mercados financieros, las asimetrías de información y la incapacidad de hacer cumplir los contratos constituyen un gran obstáculo para el acceso a los recursos financieros. La estructura financiera, no obstante, no es independiente del tamaño de la empresa. De hecho, la escala empresarial es una variable clave en el análisis de las restricciones financieras (Beck, Demirgüç-Kunt y Maksimovic, 2005). Las empresas grandes y pequeñas no tienen las mismas oportunidades de acceso a fuentes externas de financiamiento.

Los problemas relacionados con los costos de agencia, las asimetrías de información y los costos fijos de transacción generan imperfecciones en el mercado financiero. Por lo general, las pequeñas empresas son las más afectadas por estas imperfecciones, ya que su información interna puede ser bastante poco clara o, al menos, no está tan disponible para el público como la de las empresas más grandes. Las pequeñas empresas que buscan acceder a pequeños préstamos enfrentan costos de transacción más elevados y primas por riesgo más altas, debido a que su situación financiera es menos transparente y a que tienen menos garantías subsidiarias para ofrecer (Beck y Demirgüç-Kunt, 2006). Beck, Demirgüç-Kunt y Maksimovic (2005), Beck y otros (2006), y Schiffer y Weder (2001) registran resultados similares. En el último estudio también se confirma que las pequeñas empresas enfrentan mayores obstáculos al crecimiento.

En la literatura reciente sobre financiamiento empresarial se ha destacado el papel del desarrollo financiero y la protección jurídica de los acreedores externos en relación con el desempeño empresarial. Una de las principales consecuencias es que los sistemas financieros subdesarrollados pueden limitar la capacidad de inversión de las empresas. En estos estudios existen dos amplias perspectivas respecto del crédito al sector privado en distintas economías (Djankov, McLiesh y Shleifer, 2007). La primera pone énfasis en el poder de los acreedores: cuando los bancos tienen la capacidad de exigir el pago, confiscar la garantía subsidiaria o incluso asumir el control de la empresa, están dispuestos a ofrecer más crédito (Townsend, 1979). La segunda perspectiva resalta la importancia de la información en la actividad crediticia. Existe una vasta literatura en la que se analizan los problemas que plantean el riesgo moral y la selección adversa en la actividad financiera y se explica cómo estos 
factores reducen el acceso al crédito ${ }^{1}$. Cuanta más información tienen los prestamistas sobre los prestatarios, su historial de crédito y su nivel total de deuda, más se mitigan estos problemas.

En la literatura sobre los mercados de crédito se han identificado distintas formas en las que un prestamista puede resolver los problemas de pago; la más destacada es el uso de una garantía subsidiaria. El ofrecimiento de una garantía subsidiaria puede servir como mecanismo para mitigar asimetrías de información y así resolver los problemas de racionamiento del crédito. Si la tasa de interés no cumple con eficacia su papel debido a efectos indirectos sobre la calidad media de las carteras de crédito, los bancos pueden recurrir a la garantía subsidiaria. Si se considera la posibilidad de equiparar la garantía subsidiaria a una determinada tasa de interés, puede lograrse un equilibrio sin racionamiento del crédito.

Sin embargo, no todos los préstamos pueden respaldarse fácilmente con una garantía subsidiaria. La constitución de una garantía de préstamo suele ser problemática para ciertas empresas (por ejemplo, empresas nuevas, microemprendimientos y pymes) que a menudo no cuentan con suficientes activos fijos para ofrecer como garantía subsidiaria. La constitución de una garantía también supone un problema en aquellos países donde los derechos de los acreedores no están bien protegidos y donde el proceso de confiscación de la garantía es costoso y lleva mucho tiempo. En este contexto, el marco institucional para la protección jurídica de los acreedores tiene una influencia particularmente fuerte en el acceso al crédito, sobre todo para las pymes.

En La Porta y otros (1997 y 1998) y Schiantarelli (1996) se presenta un análisis de la importancia de la garantía subsidiaria en relación con los contratos de crédito y las instituciones que respaldan el uso de esta garantía. De estas publicaciones se desprenden dos datos centrales: i) el financiamiento externo es más costoso que el financiamiento interno, a menos que los préstamos estén totalmente garantizados, y ii) la prima sobre el financiamiento externo es una función inversa del valor neto de un prestatario (activos líquidos más el valor colateral de los activos ilíquidos). Los organismos de información crediticia y los registros de crédito también pueden mitigar la asimetría de información entre prestamistas y prestatarios ${ }^{2}$. El historial de préstamos y pagos de los prestatarios reduce las asimetrías de información y permite a los prestamistas determinar el potencial de pago de sus clientes. Este mecanismo crea otra forma de garantía subsidiaria - la garantía de la reputación - que los bancos pueden utilizar para analizar a posibles prestatarios ${ }^{3}$. La información sobre solvencia crediticia puede, por tanto, ser una fuente extremadamente valiosa de evaluación del riesgo crediticio, mejorada y basada en hechos para los acreedores, y, en tal sentido, puede facilitar el acceso de las pymes y de otras empresas al financiamiento. La diferencia radica, no obstante, en que mientras que los datos de crédito y otros datos relevantes de las grandes empresas en general se encuentran ampliamente disponibles, esto no suele ocurrir con la información de las pymes.

Facilitar el flujo de estos datos relacionados al crédito y otra información financiera relevante sobre las pymes ayuda a reducir sus limitaciones en materia de financiamiento. Al garantizar que los acreedores tengan un acceso rápido a información precisa, significativa y suficiente sobre las pymes se mejora de manera sistemática y oportuna su capacidad para evaluar la solvencia crediticia de estas empresas y aumentar su acceso al financiamiento mediante créditos. Usando una encuesta realizada a distintos bancos, Beck, Demirgüç-Kunt y Martínez Pería (2008) confirman la importancia de disponer de datos adecuados sobre el historial de crédito de las pymes: el 70\% de los bancos en los países en desarrollo y el $44 \%$ de los bancos en los países desarrollados que respondieron a la

1 Véase una descripción de la literatura en Stiglitz y Weiss (1981) y Freixas y Rochet (2008).

2 Los registros de crédito pueden ser privados o públicos, y sus prácticas varían en cuanto a la información que recolectan (sobre comportamiento crediticio positivo, negativo o ambos).

3 Véase información teórica sobre la reducción de la asimetría de información en Pagano y Jappelli (1993), Padilla y Pagano (1997), y Bennardo, Pagano y Piccolo (2009). 
encuesta afirmaron que la existencia de un organismo de información crediticia en su país facilitaba el otorgamiento de préstamos a las pymes.

Este estudio tiene por objeto analizar la importancia que tienen los derechos jurídicos de los acreedores y los mecanismos de intercambio de información de los prestatarios en las variaciones del acceso al crédito bancario de empresas de distintos tamaños en diferentes países. Cuando la protección jurídica es ineficaz y hay una falta de información sobre el prestatario, los bancos deben ejercer una supervisión más estricta sobre los prestatarios. Dados los costos de supervisión fijos, el otorgamiento de préstamos a pymes resulta menos rentable que el otorgamiento de préstamos a grandes empresas, por lo que cabe esperar que la falta de protección jurídica e información aumente de manera desproporcionada las restricciones financieras de las pymes.

En la mayoría de los estudios transversales no se ajusta por la posible endogeneidad de las instituciones de información y protección de los acreedores (organismos de información crediticia). Es probable, por ejemplo, que tras un aumento de los préstamos bancarios, los países tiendan a establecer registros de crédito y leyes de protección de los acreedores más estrictas. En consecuencia, es posible que una simple regresión en corte transversal entre préstamos bancarios y protección de los acreedores y organismos de información crediticia sobrestime el efecto causal de estos dos factores sobre los préstamos empresariales.

Para evitar este problema de endogeneidad, usamos variables ficticias de países para estimar un modelo Tobit de diferencias en diferencias a nivel de la empresa a fin de comparar el crédito bancario a pymes con el crédito bancario a grandes empresas en distintos países, con distintos niveles de protección jurídica e instituciones de información. Esta metodología nos permite ajustar por cualquier variable de país omitido y por el problema de endogeneidad mencionado. Para evaluar la importancia de los derechos jurídicos de los acreedores, usamos el índice de derechos de los acreedores propuesto en primer lugar por La Porta y otros (1997 y 1998). Este índice mide los derechos jurídicos de los acreedores respecto de los morosos en distintas jurisdicciones. Para evaluar la importancia de la información en términos de crédito, usamos la existencia y cobertura de organismos de información crediticia, que son los encargados de recolectar, distribuir y, en muchos casos, analizar datos sobre el comportamiento de un prestatario recabados de diversas fuentes con el propósito de que los acreedores puedan analizar a sus posibles clientes. Como ya se indicó, la información recopilada por registros de créditos públicos o privados, ya sea sobre comportamiento crediticio positivo o negativo, o ambos, varía.

Constatamos que el establecimiento de mecanismos de información crediticia -medidos, entre otras cosas, por la población que cubren los organismos de información crediticia o los registros públicos de crédito - es importante para reducir la brecha de acceso al financiamiento bancario entre pequeñas y grandes empresas. El aumento de una desviación estándar en la cobertura de las instituciones de información sobre solvencia crediticia reduce prácticamente a la mitad la brecha de financiamiento de las pequeñas empresas. En los países en que los registros de crédito cubren menos del 1\% de la población total, el porcentaje de inversión en pequeñas empresas financiado por crédito bancario corresponde solo al $40 \%$ del porcentaje de inversión en grandes empresas financiado por bancos. Esta cifra se eleva al $63 \%$ en los países en que los registros de crédito cubren más del $1 \%$ de la población total (véase el gráfico 1A).

También constatamos que el grado de las limitaciones de crédito para las pequeñas empresas depende de la calidad del marco reglamentario: en aquellos países en que los derechos de los acreedores están protegidos (y se cumplen), las empresas más pequeñas tienen un mayor acceso al crédito bancario para fines de inversión. En nuestra muestra, este efecto es grande. En los países basados en el derecho inglés (donde la protección de los acreedores es alta), el porcentaje de inversión financiado con crédito bancario en pequeñas empresas corresponde al $75 \%$ del porcentaje financiado 
en grandes empresas. Esta proporción se reduce al 50\% en los países no basados en el derecho inglés (véase el gráfico 1B).

El resto de este estudio se encuentra organizado como se detalla a continuación. En la sección II se describe brevemente la literatura empírica disponible sobre el impacto de los organismos de información crediticia y la protección jurídica en los mercados de crédito. En la sección III se detalla la metodología econométrica que se ha utilizado. En la sección IV se presentan los datos y algunos resultados incondicionales. En las secciones $\mathrm{V}$ y $\mathrm{VI}$ se registran nuestras bases de referencia y los resultados de robustez. Por último, en la sección VII se plantean las conclusiones.

\section{Un análisis de la evidencia empírica}

La evidencia empírica a nivel agregado del país respalda la idea de que el cumplimiento de los derechos jurídicos de los acreedores y el intercambio de información mediante organismos de información crediticia o registros públicos de crédito tienen un efecto positivo en los mercados de crédito en lo que respecta al acceso al crédito, las tasas de interés y las tasas de morosidad ${ }^{4}$.

Mediante el uso de datos a nivel del país, correspondientes a 129 jurisdicciones para el período 1978-2003, Djankov, McLiesh y Shleifer (2007) encuentran que tanto la protección de los acreedores como el intercambio de información tienen una correlación positiva con el crédito en relación con el producto interno bruto (PIB). Si bien ambos tipos de instituciones juegan un papel complementario en la promoción del crédito privado, los autores dan cuenta de que la eficacia de cada una de estas instituciones varía de un país a otro en virtud del tipo de sistema jurídico vigente. Mientras que la protección jurídica de los acreedores se asocia con las tradiciones del derecho inglés, los organismos de información crediticia y los registros públicos de crédito son más eficaces en países de tradición romanista.

Jappelli y Pagano (2002) proporcionan una evidencia parecida a la presentada por Djankov, McLiesh y Shleifer (2007), aunque para una muestra de países mucho más pequeña. De modo similar, en un estudio de corte transversal, Warnock y Warnock (2008) muestran que el desarrollo de mercados de crédito hipotecario tiene una correlación positiva con el establecimiento de organismos de información crediticia 5 .

La evidencia empírica a nivel de la empresa es más escasa, pero es necesaria para poder evaluar el impacto del intercambio de información en el acceso al crédito, que depende de las características de las empresas que buscan obtener un préstamo. Galindo y Miller (2001) analizaron datos de balances generales transversales (principalmente de grandes empresas que cotizan en bolsa) y encontraron que el intercambio de información reduce las limitaciones de crédito, sobre todo en el caso de empresas pequeñas y jóvenes. Estimaron ecuaciones de inversión y hallaron que la inversión era menos sensible al flujo de caja de una empresa - una medición tradicionalmente utilizada para evaluar las limitaciones de crédito - en los países con instituciones de intercambio de información más desarrolladas. Como ya se mencionó, es probable que estas estimaciones de corte transversal tengan un sesgo por exceso debido a la endogeneidad.

Love y Mylenko (2003) usan datos de la Encuesta WBES para evaluar el impacto de la existencia de un organismo de información crediticia sobre la percepción de las empresas que

4 Galindo y Micco (2007) presentan pruebas de que el desarrollo financiero también tiene un impacto en la volatilidad del crédito, al tiempo que Feldmann (2013) muestra que el desarrollo financiero también incide en las decisiones laborales de las empresas.

5 Otros autores - como el BID (2004), Powell y otros (2004), Barron y Staten (2003), y Kallberg y Udell (2003) - destacan el impacto de los organismos de información crediticia sobre el crédito privado y revelan que la información sobre solvencia crediticia ayuda a los prestamistas a reducir las tasas de morosidad. 
enfrentan limitaciones de crédito y sobre una mayor probabilidad de que una empresa dependa de un préstamo bancario. Estos autores constatan que la existencia de un organismo privado de información crediticia se asocia a situaciones en las que pocas empresas afirman tener limitaciones financieras y más empresas dependen de un crédito bancario. Este último resultado es más relevante para las pequeñas y medianas empresas.

A nivel de la empresa existe poca evidencia respecto del impacto y la interacción de la existencia de organismos de información crediticia y de políticas de protección jurídica de los acreedores. Brown, Jappelli y Pagano (2009) recurren a estimaciones de corte transversal y un panel de información sobre países en transición en Europa oriental para evaluar el papel del intercambio de información en países con derechos de acreedores y leyes empresariales débiles. Estos autores sostienen que, en el agregado, el intercambio de información se asocia con un crédito más abundante y más barato. A nivel de la empresa, sobre la base de datos de corte transversal, encuentran que el intercambio de información y la transparencia son sustitutos el uno del otro en la mejora del acceso al crédito. Este es el primer estudio en el que se incluyen datos de panel en una evaluación del impacto del intercambio de información, pero los resultados no son concluyentes en lo que respecta a la relación entre los organismos de información crediticia, la protección jurídica de los acreedores y el acceso al crédito para distintos tipos de empresas (en términos de tamaño y transparencia). Esto se debe, en parte, a que su muestra no proporciona una variación de corte transversal con respecto a la protección jurídica de los acreedores. Además, estos autores no ajustan por tendencias temporales individuales de los países durante un período en que las economías en transición estaban sufriendo diversos cambios.

Usamos una estrategia de diferencia en diferencia para analizar el impacto de la protección de los acreedores y el intercambio de información sobre el porcentaje de inversión financiado con crédito bancario. Mediante una estrategia similar y datos de corte transversal de las Encuestas WBES del Banco Mundial, Galindo y Micco (2005) muestran que una protección jurídica débil tiene un mayor impacto negativo en las pymes ${ }^{6}$. De conformidad con Djankov, McLiesh y Shleifer (2007), sostienen que la brecha en el acceso al crédito entre las pymes y las grandes empresas es mayor en países no basados en el derecho inglés.

En ninguno de estos estudios previos se analizó el impacto o la interacción de los organismos de información crediticia y las políticas de protección jurídica de los acreedores usando una metodología de diferencias en diferencias.

\section{Métodos econométricos}

Nuestra hipótesis plantea que, en comparación con las grandes empresas, las pymes deberían tener un mayor acceso relativo al crédito en países donde los derechos jurídicos de los acreedores están bien establecidos y el intercambio de información está más desarrollado. La variable dependiente en nuestro estudio es el porcentaje de financiamiento que proviene de los bancos. Dado que esta variable está restringida a entre 0 y 100, usamos el modelo de regresión censurado de Tobit e introducimos variables ficticias de países para captar efectos fijos de los países ${ }^{7}$. Si bien Greene (2004) muestra que los coeficientes de situación en el modelo Tobit, a diferencia de aquellos en los modelos Probit y Logit, no se ven afectados por el problema de parámetros incidentales, se realizan estimaciones de mínimos cuadrados ordinarios (MCO) para la robustez. Para ajustar por características relevantes a nivel de la empresa que pueden afectar el acceso al crédito bancario, se estiman modelos empíricos

\footnotetext{
6 Este es un documento de trabajo anterior centrado únicamente en la protección de los acreedores.

7 La prueba de especificación de Hausman-McFadden para la independencia de alternativas irrelevantes rechaza la hipótesis nula de que los coeficientes para el modelo con y sin variables ficticias de los países son iguales $($ chi $(13)=78,6)$.
} 
a nivel de la empresa. A esos efectos, se efectúan ajustes por variables utilizadas habitualmente en la literatura -como la vocación exportadora de la empresa, o la falta de dicha vocación, y la estructura de propiedad de la empresa (si es de propiedad estatal o de capitales extranjeros) - y se utilizan variables ficticias por sector que indican el área en que opera la empresa. Para captar la diferencia en la brecha de financiamiento asociada con distintos niveles de intercambio de información y protección de los acreedores, se incluyen también variables ficticias de tamaño (pequeña y mediana) e interacciones entre estas variables ficticias y las medidas de intercambio de información y protección de los acreedores.

Se analizan las variaciones país-empresa mediante la estimación del siguiente modelo Tobit:

$$
C_{i j c}=\left\{\begin{array}{lll}
C_{i j c}^{*} & \text { si } & 0<C_{i j c}^{*}<1 \\
0 & \text { si } & C_{i j c}^{*} \leq 0 \\
100 & \text { si } & C_{i j c}^{*} \geq 1
\end{array}\right.
$$

donde $C^{*}$ es la siguiente variable latente:

$$
\begin{aligned}
& C_{i j c}=\alpha_{j}+\alpha_{c}+\delta X_{i j c}+\delta_{1} \operatorname{Small}_{i j c}+\delta_{2} \text { Medium }_{i j c}+\delta_{3} \operatorname{Small}_{i j c} * \operatorname{Inf}_{c} \\
& +\delta_{4} \text { Medium }_{i j c} * \operatorname{Inf}_{c}+\delta_{5} \operatorname{Small}_{i j c} * C R_{c}+\delta_{6} \text { Medium }_{i j c} * C R_{c}+\varepsilon_{i j c}
\end{aligned}
$$

donde $C_{j j c}$ denota el porcentaje de inversión financiado con crédito bancario en la empresa $i$, el sector $j$ y el país $c$; $\alpha_{j}$ y $\alpha_{c}$ son efectos fijos del sector y del país; $X_{i j c}$ es un vector de variables específicas de la empresa; $\operatorname{Small}_{i j c}$ es una variable ficticia equivalente a 1 si la empresa es pequeña; $\operatorname{Inf}_{c}$ es una medida de intercambio de información en el país $c$; $C R_{c}$ es una medida de protección jurídica de los acreedores, y $\varepsilon_{i j c}$ es un término de error normal. En algunas especificaciones incluimos términos de interacción entre $\operatorname{Inf} f_{c}$ y $C R_{c}$.

A priori se esperaría un coeficiente negativo para las variables ficticias Small (Pequeña) y Medium (Mediana), ya que las pequeñas y medianas empresas tienen menos acceso al crédito bancario que las grandes empresas (grupo testigo). Las principales variables de interés son variables ficticias de tamaño que interactúan con $C R$ e Inf. Se espera un signo positivo para cada una de estas cuatro variables. Las mejoras en los derechos de los acreedores o la creación de registros de crédito (mejor información) deberían aumentar el acceso al crédito bancario de todas las empresas (principal efecto), y en particular de las pymes (efecto adicional).

Además, se procede a ajustar por efectos fijos a nivel del país para captar cualquier variable institucional o macroeconómica que también pueda incidir en el acceso al crédito bancario. En particular, las variables ficticias de los países dan cuenta del principal efecto de una mayor solidez en los derechos jurídicos de los acreedores y el intercambio de información. Dado que las variables ficticias de tamaño interactúan con variables que no varían a nivel del país, se utilizan errores estándar agrupados para ajustarlas ${ }^{8}$. Esto es sumamente importante, ya que las variables que interactúan con las variables de tamaño no varían a nivel de la empresa, sino solo a nivel del país. Moulton (1990) demostró los importantes sesgos por defecto en los errores estándar estimados que pueden resultar de estimar los efectos de las variables explicativas agregadas sobre las variables de respuesta específicas individuales (en este caso, específicas de la empresa). Los errores estándar agrupados ayudan a reducir ese sesgo. Se ponderan las observaciones por el inverso de la cantidad de empresas en cada celda de tamaño del país para ajustar por las distintas cantidades de empresas en los diferentes países ${ }^{9}$. También ajustamos por efectos específicos del sector.

\footnotetext{
8 En especial, agrupamos a nivel de tamaño del país. Véanse Moulton (1990) y Judson y Owen (1996).

9 Sin ponderaciones, los países con más observaciones marcarán el rumbo de los resultados, aunque nuestras variables de interés solo varían entre un país y otro.
} 
La elección de la metodología empírica empleada en este estudio se relaciona estrechamente con la reciente investigación de Greene sobre efectos fijos en modelos de variable dependiente limitada. En muchos estudios a nivel de la empresa, los autores han optado por usar modelos Tobit de efecto aleatorio para estimar el impacto de variables que afectan a todo el país sobre indicadores truncados específicos de la empresa, como el porcentaje de inversión financiado por el crédito, donde la contabilización de los efectos individuales parece relevante ${ }^{10}$. Greene (2002 y 2004), no obstante, muestra que, si las variables indicativas no se encuentran no correlacionadas con los efectos individuales (una suposición generalmente difícil de aceptar), el modelo de efecto aleatorio puede derivar en estimaciones sesgadas de los parámetros de la pendiente del modelo. En ese caso, la metodología preferida es el modelo Tobit de efecto fijo, ya que el sesgo en los parámetros de la pendiente atribuido al problema de parámetros incidentales tiende a ser insignificante.

Los efectos fijos a nivel del país nos permiten abordar los componentes específicos de cada país, observados y no observados, así como, en algunos casos, la endogeneidad parcial y la causalidad inversa. Todo aumento en el crédito total que lleva al establecimiento de organismos de información crediticia y mecanismos de protección de los acreedores se ajusta por el efecto fijo. Únicamente los cambios atípicos en la cantidad relativa de crédito a las pymes, que suponen cambios en los registros de crédito y los derechos de los acreedores a nivel del país, no serán considerados por el efecto fijo del país; por tanto, la causalidad inversa seguirá teniendo cierto alcance.

\section{Datos}

En esta sección se describen las fuentes de datos y variables utilizadas en el análisis empírico. La principal fuente de datos es la Encuesta WBES ${ }^{11}$. Otras fuentes incluyen varios documentos de investigación que ofrecen valiosos datos acerca del establecimiento de organismos de información crediticia y disposiciones reglamentarias sobre la protección de los acreedores en todo el mundo ${ }^{12}$. A los efectos de este estudio, la variable dependiente es el uso de empresas de distinto tamaño. Nuestro propósito es probar si el acceso al crédito - definido como el porcentaje de inversión financiado con crédito bancario - depende del nivel de protección jurídica de los acreedores, el establecimiento de mecanismos de intercambio de información, el tamaño de las empresas o la interacción entre el tamaño, por una parte, y la protección de los acreedores y el intercambio de información, por la otra.

Los resultados de la Encuesta WBES proporcionan un conjunto de datos a nivel de la empresa que consiste en respuestas de más de 10.000 empresas de todo el mundo a preguntas relacionadas con el ambiente de los negocios en un país. La encuesta incluye preguntas referidas a la estructura de financiamiento de las empresas. Se pidió a los gerentes comerciales que indicaran qué porcentaje de la inversión se financió en el último año a través de las siguientes fuentes: i) beneficios acumulados, ii) fondos de familiares y amigos, iii) fondos propios, iv) crédito de proveedores, v) contratos de arrendamiento financiero, vi) prestamistas, vii) otro apoyo del sector público, viii) bancos comerciales locales, ix) bancos extranjeros, $\mathrm{x}$ ) bancos de desarrollo y xi) otros. A los efectos de nuestro análisis, definimos la variable dependiente como la suma del porcentaje de inversión financiado con crédito proporcionado por bancos comerciales locales y bancos extranjeros; a esto lo denominamos "acceso al crédito bancario".

Al construir la variable "acceso al crédito bancario", se tuvo mucho cuidado de excluir datos erróneos. Se dejaron de lado a todas las empresas que informaron porcentajes de fuentes de

\footnotetext{
10 Véase, por ejemplo, Beck, Demirgüç-Kunt y Maksimovic (2001).

${ }^{11}$ Este conjunto de datos se ha utilizado en varios estudios de corte transversal. Véanse, por ejemplo, Beck, Demirgüç-Kunt y Maksimovic (2005), y Beck y otros (2006).

12 Véanse, por ejemplo, La Porta y otros (1997 y 1998), y Djankov, McLiesh y Shleifer (2007).
} 
financiamiento que totalizaban menos del 90\% o más del 110\%. De este modo, quedó abierta la posibilidad de pequeños errores en la adición, pero se eliminaron datos excesivamente erróneos.

Otra variable esencial a nivel de la empresa en este estudio es el tamaño de las empresas. Estos datos también se obtuvieron de la Encuesta WBES, que clasifica a las empresas en tres grupos según su tamaño: las pequeñas empresas se definen como aquellas con más de 5 y menos de 50 trabajadores, las empresas medianas son las que tienen más de 50 y menos de 500 empleados y las grandes empresas son las que cuentan con más de 500 trabajadores. Otras variables a nivel de la empresa incluidas en el análisis empírico y que pueden afectar el acceso al financiamiento son: la estructura de propiedad de la empresa (si es de propiedad estatal o de capitales extranjeros), la vocación exportadora y el sector económico en que opera la empresa ${ }^{13}$.

En el cuadro 1 se presentan algunas estadísticas descriptivas básicas para la variable dependiente de los 61 países en que los datos del organismo de información crediticia y las leyes de protección de los acreedores pueden equipararse a los datos de la Encuesta WBES. La empresa media en la muestra financia el 16,2\% de su inversión con crédito bancario. Como es de esperar, las grandes empresas financian un mayor porcentaje de la inversión con crédito que las pymes, ya que las primeras tienen menores asimetrías de información y más garantías, por lo que les resulta más fácil obtener acceso a los mercados de crédito. Las empresas exportadoras - definidas como aquellas empresas en las cuales las exportaciones representan al menos el 1\% del total de ventas - tienen mayor acceso al crédito que otras empresas. Esto puede deberse a que la actividad exportadora es indicativa de una alta productividad y, por lo tanto, de altas probabilidades de pago a los acreedores, con lo que reduce las limitaciones financieras. Esto ocurriría con empresas de todos los tamaños. En la muestra no se registran diferencias incondicionales relevantes entre los porcentajes de inversión financiados por pymes de capitales extranjeros.

Cuadro 1

Inversión financiada con crédito bancario: estadísticas descriptivas (En niveles y porcentajes)

\begin{tabular}{|c|c|c|c|c|c|}
\hline & & Total & Exportación & $\begin{array}{c}\text { Empresas de capitales } \\
\text { extranjeros }\end{array}$ & $\begin{array}{c}\text { Empresas de } \\
\text { propiedad estatal }\end{array}$ \\
\hline \multirow{2}{*}{$\begin{array}{l}\text { Totala } \\
6616\end{array}$} & Media & 16,2 & 23,2 & 11,6 & 23,3 \\
\hline & Desviación estándar & 27,0 & 30,4 & 24,1 & 31,7 \\
\hline \multirow{2}{*}{$\begin{array}{l}\text { Pequeñas } \\
2803\end{array}$} & Media & 11,3 & 17,5 & 12,1 & 14,2 \\
\hline & Desviación estándar & 22,8 & 26,8 & 27,4 & 26,1 \\
\hline \multirow{2}{*}{$\begin{array}{l}\text { Medianas } \\
2797\end{array}$} & Media & 17,5 & 22,4 & 9,3 & 20,8 \\
\hline & Desviación estándar & 27,7 & 29,9 & 21,8 & 30,5 \\
\hline \multirow{2}{*}{$\begin{array}{l}\text { Grandes } \\
1014\end{array}$} & Media & 26,1 & 29,1 & 17,2 & 32,0 \\
\hline & Desviación estándar & 32,0 & 32,9 & 27,5 & 34,2 \\
\hline
\end{tabular}

Fuente: Elaboración propia, sobre la base de Banco Mundial, World Business Environment Survey (WBES).

a No todas las empresas tienen esta variable, por lo cual el total no corresponde a la suma de las empresas por tamaños.

Para medir el desarrollo de los registros de crédito, se utilizaron datos del proyecto Doing Business del Banco Mundial. Las principales variables son la existencia de cualquier registro de crédito, una variable ficticia equivalente a 1 si hay un registro público de crédito o un organismo privado de información crediticia, y la cobertura de registros públicos y privados. La cobertura de un organismo privado de información crediticia da cuenta de la cantidad de personas o empresas registradas por

${ }^{13}$ El conjunto de datos no incluye la cantidad de empleados, las cifras de ventas ni el nivel de activos. Por lo tanto, en este estudio se utiliza la única variable de tamaño disponible. 
un organismo público o privado de información crediticia, con información sobre historial de pagos, deudas impagas o crédito pendiente. La cantidad se expresa como porcentaje de la población adulta. Además, se construyó un índice que toma el máximo entre aquellos dos valores como la variable relevante para la economía y se analizó el papel de cada tipo de cobertura en forma individual. Por ejemplo, si un país tiene un organismo privado de información crediticia que cubre 550 habitantes por cada 1.000 y un registro público de crédito que solo cubre 200 habitantes por cada 1.000, entonces se escoge 550 (el más grande de los dos). El motivo es evitar la duplicación de prestatarios (muchos de los cuales pueden aparecer en ambos registros). En un ejercicio no informado, se utilizó cada una de las medidas de cobertura por separado. Esta medida otorga cierta información sobre el número de pymes que pueden estar cubiertas por los registros de crédito. Por ejemplo, en el caso de Chile, un país de la muestra con un nivel de desarrollo medio, el registro privado de crédito tiene 227 entradas cada 1.000 adultos. En ese mismo año, dicho país tenía 1,9 grandes empresas cada 1.000 adultos, 1,5 empresas medianas cada 1.000 adultos y 25 pequeñas empresas y 123 microempresas cada 1.000 adultos $^{14}$. En el anexo se incluyen los datos por país usados en el estudio.

Para representar el estado de la protección jurídica de los acreedores se recurre a un conjunto de variables citado con frecuencia en la literatura relacionada ${ }^{15}$. Estas variables son medidas de ciertos tipos de instituciones y de normas y reglamentos que afectan directamente la capacidad de un acreedor para confiscar la garantía de manera efectiva y eficaz ${ }^{16}$. Siguiendo a Galindo y Micco (2007), se usa una medida de derechos efectivos de los acreedores que combina una variable jurídica que refleja la protección de los acreedores sobre la base de La Porta y otros (1997) y un indicador del estado de derecho (derivado del Banco Mundial). Esta variable capta no solo el marco reglamentario en torno a los derechos de los acreedores en los procedimientos de quiebra, sino también el grado de cumplimiento con las leyes de quiebra. Por su parte, la protección de los derechos de los acreedores es representada mediante el tipo de sistema jurídico vigente ${ }^{17}$. Aquí se recurrió a la proposición avalada por La Porta y otros (1997) de que los países con regímenes de derecho común se caracterizan por tener una mejor protección de los acreedores.

En el gráfico 1 y el cuadro 2 se presentan algunas estadísticas básicas que sustentan el estudio econométrico. En el gráfico 1 se muestra el porcentaje medio de la inversión de empresas de distinto tamaño que ha sido financiado con crédito bancario en países en los que el desarrollo de organismos de información crediticia ha alcanzado distintos niveles (véase el gráfico 1A) y que tienen distintos sistemas jurídicos (véase el gráfico 1B) ${ }^{18}$.

El desarrollo de los organismos de información crediticia se mide como el porcentaje de la población cubierto por un organismo privado de información crediticia o un registro público de crédito. Con el propósito de tener una cantidad similar de países en cada grupo, dividimos la muestra en países con cobertura superior o inferior al 1\%. Como era de esperar, las empresas más grandes pueden acceder a más crédito para financiar sus inversiones. En los países con registros de crédito más sólidos, no obstante, las empresas de todos los tamaños tienen más disponibilidad de crédito que en los países donde los organismos de información crediticia tienen menor presencia. La diferencia

\footnotetext{
${ }^{14}$ En Chile, las empresas grandes, medianas y pequeñas se definen como aquellas que tienen ventas anuales por más de 3,8 millones de dólares, 961.000 dólares y 92.000 dólares, respectivamente.

15 Véanse La Porta y otros (1997 y 1998), y Galindo y Micco (2007).

${ }^{16}$ El índice de derechos de los acreedores mide: i) si hay restricciones, como el consentimiento del acreedor, cuando un deudor solicita una reorganización; ii) si los acreedores con garantía pueden confiscar la garantía tras la aprobación de la solicitud de reorganización (en otras palabras, si no hay una paralización automática o una congelación de activos ordenada judicialmente); iii) si los acreedores con garantía reciben el pago en primer lugar derivado de los beneficios de la liquidación de una empresa en situación de quiebra, y iv) si un administrador, y no la gerencia, es responsable del manejo del negocio durante la reorganización.

17 Varios autores han vinculado una tradición jurídica basada en el derecho inglés a una mejor protección de los acreedores. Véase, por ejemplo, La Porta y otros (1997 y 1998).

18 Como valor de corte, usamos una cobertura máxima del $1 \%$.
} 
en el acceso al crédito es proporcionalmente mayor para las pequeñas empresas. Cuando dividimos la muestra en países basados y no basados en el derecho inglés obtenemos resultados similares. En ambos grupos, las grandes empresas tienen más acceso al crédito que las pequeñas empresas, pero esta diferencia es bastante insignificante en los países basados en el derecho inglés.

Además, en el cuadro 2, la muestra se divide en países con índices de cobertura alta y baja para registros de crédito u organismos de información crediticia, usando como límite un nivel de cobertura del 1\% de la población total (10\%); la muestra también se divide de acuerdo con el nivel de protección de derechos de los acreedores. Como era de esperar, en cada cuadrante, el porcentaje de inversión financiado con crédito bancario aumenta con el tamaño de las empresas. También como era de esperar, el porcentaje de financiamiento es mayor en los países con una mayor protección de los acreedores para cualquier segmento de tamaño de empresas. Resulta especialmente interesante destacar cómo el porcentaje de crédito en las pequeñas empresas alcanza un nivel similar en los países con una fuerte protección de los acreedores y sin registro de crédito, y en los países con una débil protección de los acreedores y registro de crédito. La presencia de un organismo de información crediticia o de un registro de crédito, por lo tanto, parece compensar las deficiencias en las reglamentaciones de los derechos de los acreedores. Esto es importante para los países en desarrollo, ya que una organización institucional débil en el sector financiero, algo que podría ser difícil de solucionar en el corto plazo, podría compensarse con una mayor oferta de información.

Gráfico 1

Inversión financiada con crédito bancario, por tamaño de la empresa

(En porcentajes)

A. Países con organismos de información crediticia según cobertura máxima

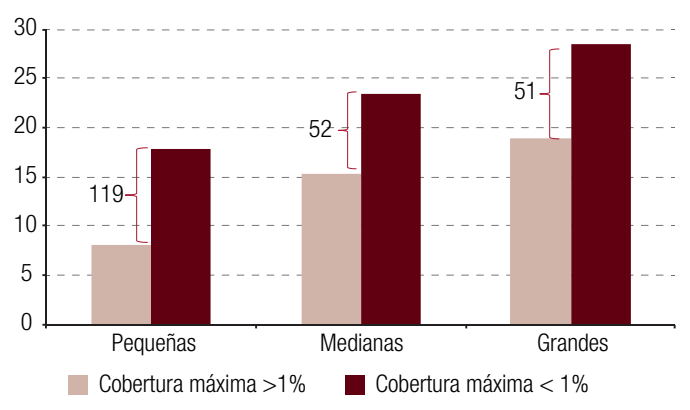

B. Países basados y no basados en el derecho inglés

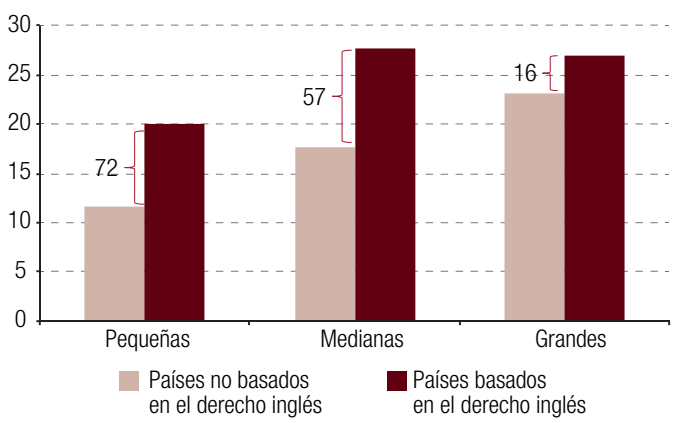

Fuente: Elaboración propia, sobre la base de Banco Mundial, World Business Environment Survey (WBES).

Nota: Se excluye a Portugal por tener el mismo número de observaciones en cada grupo.

Cuadro 2

Inversión financiada con crédito bancario, por tamaño de la empresa, presencia o ausencia de mecanismos de intercambio de información y tipo de sistema jurídico

$$
\text { (En porcentajes) }
$$

\begin{tabular}{|c|c|c|c|c|c|c|}
\hline & \multicolumn{3}{|c|}{ Países no basados en el derecho inglés } & \multicolumn{3}{|c|}{ Países basados en el derecho inglés } \\
\hline & Pequeñas & Medianas & Grandes & Pequeñas & Medianas & Grandes \\
\hline Sin registro público o privado & 5,4 & 10,3 & 13,6 & 25,9 & 34,4 & 35,0 \\
\hline Cantidad de países & 18 & 18 & 18 & 4 & 4 & 4 \\
\hline Con registro público o privado & 15,2 & 21,7 & 28,7 & 16,8 & 24,0 & 22,3 \\
\hline Cantidad de países & 32 & 32 & 31 & 7 & 7 & 7 \\
\hline
\end{tabular}

Fuente: Elaboración propia, sobre la base de Banco Mundial, World Business Environment Survey (WBES). 


\section{Resultados de referencia}

En el cuadro 3 se muestran los resultados de referencia. En lo que respecta a los controles a nivel de la empresa, se encuentra que las exportadoras financian con préstamos bancarios alrededor de un $10 \%$ más de su inversión que las empresas que atienden el mercado interno ${ }^{19}$. No se hallan grandes diferencias entre los porcentajes de financiamiento de las empresas de propiedad estatal o de capitales extranjeros. Por último, si bien esto no se incluye en los cuadros, las empresas que operan en el sector manufacturero, quizás debido al carácter tangible de sus activos, tienen mayor acceso a préstamos bancarios. En un país con una cobertura media de información de crédito (113), las pequeñas empresas financian con crédito alrededor de 30 puntos porcentuales menos de su inversión que las grandes empresas, al tiempo que el diferencial correspondiente para las empresas medianas ronda los 11,5 puntos porcentuales 20 .

Enfocándose en las variables de interés para este estudio, encontramos que el desarrollo de mecanismos de intercambio de crédito altera la brecha de financiamiento entre grandes y pequeñas empresas. En la columna 1 se indica que un aumento de una desviación estándar en la cobertura de las instituciones de intercambio de información de crédito (119 cada 1.000 habitantes) por encima del promedio (113) reduce la brecha de financiamiento entre grandes y pequeñas empresas a casi 22 puntos porcentuales (de 30 puntos) y la brecha entre empresas grandes y medianas a 8,5 puntos porcentuales (de 11,5) ${ }^{21}$. El efecto de los mecanismos de intercambio de información no solo es estadísticamente significativo, sino que también es bastante grande en relación con las brechas de financiamiento prevalecientes entre grandes y pequeñas empresas.

En la columna 2 también se muestra que la presencia de instituciones de intercambio de información de crédito influye a la hora de explicar la brecha de financiamiento entre grandes y pequeñas empresas. La variable ficticia usada para representar la existencia de un registro público o un organismo privado de información crediticia indica que, en aquellos países en los que operan dichas instituciones, la brecha entre grandes y pequeñas empresas se reduce 39 puntos porcentuales. En el caso de las empresas medianas, la brecha se reduce 17 puntos porcentuales. En la columna 3 se muestran resultados cualitativamente similares cuando las variables ficticias se usan en relación con la existencia de instituciones de intercambio de información y su cobertura. La existencia de organismos de intercambio de información crediticia incrementa notoriamente el acceso de las empresas al crédito, con un impacto diferencial en las empresas más pequeñas.

En la columna 4 se señala si hay alguna diferencia entre los registros de crédito que incluyen información positiva (buenos antecedentes de pago) y los registros que incluyen solo antecedentes negativos en sus informes de crédito. No se encontró ninguna diferencia estadísticamente significativa entre la inclusión de información positiva y negativa y la inclusión de información únicamente negativa en los informes de crédito.

Una regresión no presentada incluye interacciones adicionales que separan la cobertura de registros públicos de crédito y organismos privados de información crediticia. Los resultados indican que el impacto en las pequeñas y medianas empresas no presenta una diferencia significativa cuando se discrimina entre los dos tipos de instituciones, aunque el impacto en las empresas medianas pareciera responder principalmente a información proveniente de organismos privados de información crediticia.

19 Como medida de robustez, usamos una definición diferente de empresas exportadoras (exportaciones >10\% de ventas), pero los resultados no cambian.

20 Estos resultados provienen de la columna 1. Para calcular el valor para las pequeñas y medianas empresas, tomamos $C L=0,5$ $(C L$ es 0 o 1) y cobertura máxima $=113$ (la cobertura máxima media en la muestra): $-30=-48+0,07 \times 113+19,9 \times 0,5$.

${ }^{21}$ La reducción estimada en la brecha de crédito es $119^{\star} 0,07$ para las pequeñas empresas y $119^{\star} 0,025$ para las empresas medianas. 
Cuadro 3

Resultados econométricos de referencia

\begin{tabular}{|c|c|c|c|c|c|c|c|c|}
\hline $\begin{array}{l}\text { Variable dependiente: porcentaje } \\
\text { de inversión financiado con crédito } \\
\text { bancario (nivel de empresa) }\end{array}$ & (1) & (2) & (3) & (4) & (5) & (6) & (7) & (8) \\
\hline \multirow{2}{*}{ Empresas exportadoras } & 10,546 & 10,195 & 10,191 & 10,174 & 9,690 & 10,248 & 9,812 & 3,781 \\
\hline & {$[2,369]^{\star \star \star}$} & {$[2,366]^{\star \star \star}$} & {$[2,379]^{\star \star \star}$} & {$[2,359]^{\star \star *}$} & {$[2,320]^{\star \star *}$} & {$[2,335]^{\star * *}$} & {$[2,339]^{\star * *}$} & {$[1,058]^{\star \star *}$} \\
\hline \multirow{2}{*}{ Propiedad estatal (empresa) } & $-6,535$ & $-7,740$ & $-8,106$ & $-7,613$ & $-6,550$ & $-5,634$ & $-6,903$ & $-4,265$ \\
\hline & {$[4,201]$} & {$[4,216]^{*}$} & {$[4,224]^{*}$} & {$[4,224]^{*}$} & {$[4,177]$} & {$[4,182]$} & {$[4,212]$} & {$[1,741]^{\star *}$} \\
\hline \multirow{2}{*}{ Propiedad de capitales extranjeros (empresa) } & $-0,266$ & $-0,250$ & $-0,039$ & $-0,336$ & $-0,266$ & $-0,462$ & $-0,232$ & 0,116 \\
\hline & {$[3,080]$} & {$[3,075]$} & {$[3,071]$} & {$[3,076]$} & {$[3,067]$} & {$[3,093]$} & {$[3,064]$} & {$[1,456]$} \\
\hline \multirow{2}{*}{ Pequeñas empresas } & $-48,184$ & $-66,341$ & $-64,858$ & $-68,018$ & $-57,882$ & $-43,239$ & $-58,035$ & $-10,690$ \\
\hline & {$[4,980]^{\star \star \star}$} & {$[9,290]^{\star \star \star}$} & {$[9,295]^{\star \star \star}$} & {$[9,323]^{\star \star \star}$} & {$[8,264]^{\star \star \star}$} & {$[4,794]^{\star \star \star}$} & {$[8,339]^{\star \star \star}$} & {$[1,702]^{\star \star \star}$} \\
\hline \multirow{2}{*}{ Empresas medianas } & $-23,681$ & $-32,804$ & $-32,696$ & $-34,610$ & $-27,403$ & $-19,078$ & $-27,365$ & $-3,627$ \\
\hline & {$[4,007]^{\star \star \star}$} & {$[6,859]^{\star \star \star}$} & {$[6,879]^{\star \star \star}$} & {$[7,199]^{\star \star *}$} & {$[6,080]^{\star \star *}$} & {$[3,735]^{\star \star \star}$} & {$[6,121]^{\star \star \star}$} & {$[1,346]^{\star \star *}$} \\
\hline Cobertura del registro de crédito & 0,070 & & 0,042 & & & 0,058 & 0,028 & 0,013 \\
\hline Pequeñas empresas & {$[0,013]^{\star \star *}$} & & {$[0,017]^{* *}$} & & & {$[0,013]^{\star \star \star}$} & {$[0,016]^{*}$} & {$[0,005]^{\star *}$} \\
\hline Cobertura del registro de crédito & 0,025 & & 0,010 & & & 0,015 & $-0,001$ & 0,004 \\
\hline Empresas medianas & {$[0,010]^{\star \star}$} & & {$[0,011]$} & & & {$[0,011]$} & {$[0,014]$} & {$[0,004]$} \\
\hline Registro público o privado & & 39,089 & 28,189 & 35,888 & 33,617 & & 27,299 & \\
\hline Pequeñas empresas & & {$[8,962]^{\star * \star}$} & {$[10,500]^{\star * \star}$} & {$[11,144]^{\star \star \star}$} & {$[8,315]^{\star \star *}$} & & {$[9,401]^{\star \star *}$} & \\
\hline Registro público o privado & & 17,511 & 15,440 & 13,970 & 14,934 & & 15,243 & \\
\hline Empresas medianas & & {$[6,817]^{\star \star}$} & {$[7,682]^{\star \star}$} & {$[7,934]^{\star}$} & {$[6,464]^{\star \star}$} & & {$[7,423]^{\star \star}$} & \\
\hline Registro con información positiva & & & & 5,787 & & & & \\
\hline Pequeñas empresas & & & & {$[9,737]$} & & & & \\
\hline Registro con información positiva & & & & 6,296 & & & & \\
\hline Empresas medianas & & & & 6,296 & & & & \\
\hline País basado en el derecho inglés & 19,878 & 32,019 & 26,009 & 32,643 & & & & 6,510 \\
\hline Pequeñas empresas & {$[7,833]^{\star \star}$} & {$[9,042]^{\star \star \star}$} & {$[9,966]^{\star \star \star}$} & {$[8,783]^{\star \star \star}$} & & & & {$[2,623]^{\star \star}$} \\
\hline País basado en el derecho inglés & 18,764 & 22,334 & 21,293 & 23,023 & & & & 7,884 \\
\hline Empresas medianas & {$[5,407]^{\star \star *}$} & {$[5,588]^{\star \star *}$} & {$[5,838]^{\star \star *}$} & {$[5,675]^{\star \star \star}$} & & & & {$[2,369]^{\star \star \star}$} \\
\hline Efecto de derechos de los acreedores (país) & & & & & 26,992 & 17,790 & 21,639 & \\
\hline Pequeñas empresas & & & & & {$[4,522]^{\star \star \star}$} & {$[5,052]^{\star \star *}$} & {$[5,551]^{\star \star \star}$} & \\
\hline Efecto de derechos de los acreedores (país) & & & & & 17,416 & 15,430 & 17,627 & \\
\hline Empresas medianas & & & & & {$[4,425]^{\star * *}$} & {$[4,729]^{\star \star *}$} & {$[5,099]^{\star \star *}$} & \\
\hline Observaciones & 6470 & 6604 & 6604 & 6604 & 6470 & 6604 & 6604 & 6604 \\
\hline Efectos fijos del país & Sí & Sí & Sí & Sí & Sí & Sí & Sí & Sí \\
\hline Efectos fijos del sector & Sí & Sí & Sí & Sí & Sí & Sí & Sí & Sí \\
\hline Cantidad de países & 61 & 61 & 61 & 61 & 61 & 61 & 61 & 61 \\
\hline
\end{tabular}

Fuente: Banco Mundial, World Business Environment Survey (WBES) y S. Djankov, C. McLiesh y A. Shleifer, "Private credit in 129 countries", Journal of Financial Economics, vol. 84, № 2, Amsterdam, Elsevier, 2007.

Nota: Errores estándar robustos entre paréntesis. Agrupamientos por tamaño de país. * significativo al 10\%; ** significativo al $5 \%$; ${ }^{* * *}$ significativo al $1 \%$.

Para estudiar el papel de la protección jurídica de los acreedores, se incluyó la interacción de las variables ficticias de tamaño de la empresa con las medidas de protección de los derechos de los acreedores. En las columnas 1 a 4 se presenta una interacción entre el tamaño de la empresa y una variable ficticia que indica si un país tiene un sistema basado en el derecho inglés, lo que ha resultado 
ser una buena variable sustitutiva para los derechos efectivos de los acreedores (CL). La brecha de crédito entre pequeñas y grandes empresas es entre 20 y 30 puntos porcentuales menor en países con regímenes basados en el derecho inglés en comparación con países que tienen otros sistemas jurídicos. En el caso de las empresas medianas, la brecha con las grandes empresas se reduce entre 18 y 32 puntos porcentuales.

Siguiendo a Galindo y Micco (2007), en las columnas 5 a 7 se agregó una interacción del tamaño con un indicador de protección de los derechos efectivos de los acreedores sobre la base de la interacción señalada por La Porta y otros (1997 y 1998) entre los derechos de los acreedores y el indicador de estado de derecho del conjunto de datos de indicadores mundiales de gobernabilidad 22 . Encontramos resultados muy sólidos respecto del impacto de las reglamentaciones de los derechos de los acreedores en la reducción de la brecha de financiamiento entre pequeñas y grandes empresas y entre empresas medianas y grandes. El aumento de una desviación estándar en nuestra medida de derechos efectivos de los acreedores $(0,516)$ reduce la brecha entre pequeñas y grandes empresas entre 9 y 14 puntos porcentuales y la brecha entre empresas medianas y grandes entre 8 y 9 puntos porcentuales. En una regresión no presentada en este estudio en la que se utilizó el logaritmo de la cantidad de días que el sistema de justicia necesita para ejecutar un contrato como una medida de protección de los acreedores, se obtuvieron resultados similares.

Por último, en la columna 8 se reestimó la especificación de la columna 1 usando mínimos cuadrados ordinarios. Los coeficientes estimados tienen el mismo signo esperado y son significativos a niveles convencionales. Debido a la naturaleza censora de los datos, no resulta sorprendente que las pendientes estimadas sean más pequeñas en valores absolutos.

La mejora de la protección de los derechos de los acreedores es el principal orientador de políticas para reducir la brecha de financiamiento. Sin embargo, y especialmente en el caso de las pequeñas empresas, el esfuerzo para reforzar los derechos efectivos de los acreedores puede fortalecerse con esfuerzos para desarrollar mecanismos de intercambio de información. Estos esfuerzos proporcionarán una mayor recompensa si los beneficios de los mecanismos de información son mayores en países con baja protección de los acreedores. Para probar esta hipótesis, las columnas 1, 2, 4 y 5 del cuadro 3 se calculan en el cuadro 4, al tiempo que se incluye un término de interacción entre el intercambio de información y la protección de los acreedores. Para cada una de las cuatro especificaciones, el término de interacción es negativo para las pequeñas y medianas empresas y es estadísticamente significativo en todos los casos para las pequeñas empresas. Esto supone que el efecto beneficioso de las instituciones de intercambio de información es mayor en los países con baja protección de los acreedores. Los países sin regímenes basados en el derecho inglés pueden, por tanto, compensar la ausencia de derechos efectivos de los acreedores en sus mercados de crédito con el establecimiento de instituciones de intercambio de información.

En suma, nuestros resultados de referencia indican que la protección jurídica de los acreedores y el desarrollo de organismos de información crediticia públicas o privadas tienen una fuerte correlación con el acceso a los mercados de crédito, sobre todo para las pequeñas empresas. En la sección VI ajustamos por el nivel de desarrollo y distintas submuestras con el propósito de lograr una mejor comprensión de la robustez de estos resultados.

22 Véase Kaufmann, Kraay y Mastruzzi (2009). 


\section{Cuadro 4}

Resultados econométricos cuando se ajusta por el efecto de interacción entre el intercambio de información y la protección de los acreedores

\begin{tabular}{|c|c|c|c|c|}
\hline $\begin{array}{l}\text { Variable dependiente: porcentaje de inversión financiado } \\
\text { con crédito bancario (nivel de empresa) }\end{array}$ & (1) & (2) & (3) & (4) \\
\hline \multirow{2}{*}{ Empresas exportadoras } & 10,300 & 10,000 & 10,084 & 9,499 \\
\hline & {$[2,359]^{\star \star \star}$} & {$[2,339]^{\star \star \star}$} & {$[2,330]^{\star \star *}$} & {$[2,307]^{\star \star \star}$} \\
\hline \multirow{2}{*}{ Propiedad estatal (empresa) } & $-7,158$ & $-8,763$ & $-5,810$ & $-6,920$ \\
\hline & {$[4,203]^{*}$} & {$[4,212]^{\star \star}$} & {$[4,177]$} & {$[4,165]^{*}$} \\
\hline \multirow{2}{*}{ Propiedad de capitales extranjeros (empresa) } & 0,037 & $-0,278$ & $-0,522$ & $-0,263$ \\
\hline & {$[3,076]$} & {$[3,057]$} & {$[3,083]$} & {$[3,059]$} \\
\hline \multirow{2}{*}{ Pequeñas empresas } & $-51,739$ & $-72,842$ & $-43,978$ & $-57,367$ \\
\hline & {$[5,693]^{\star \star \star}$} & {$[11,168]^{\star \star \star}$} & {$[4,888]^{\star \star \star}$} & {$[8,188]^{\star \star \star}$} \\
\hline \multirow{2}{*}{ Empresas medianas } & $-24,723$ & $-34,245$ & $-19,475$ & $-26,579$ \\
\hline & {$[4,551]^{\star \star \star}$} & {$[7,805]^{\star \star \star}$} & {$[3,789]^{\star \star *}$} & {$[5,927]^{\star * *}$} \\
\hline Registro público o privado & & 47,353 & & 33,772 \\
\hline Pequeñas empresas & & {$[11,224]^{\star \star \star}$} & & {$[8,357]^{\star * *}$} \\
\hline Registro público o privado & & 19,290 & & 14,535 \\
\hline Empresas medianas & & {$[8,177]^{\star *}$} & & {$[6,368]^{\star *}$} \\
\hline Cobertura del registro de crédito & 0,092 & & 0,073 & \\
\hline Pequeñas empresas & {$[0,018]^{\star \star \star}$} & & {$[0,018]^{\star \star \star}$} & \\
\hline Cobertura del registro de crédito & 0,032 & & 0,024 & \\
\hline Empresas medianas & {$[0,015]^{\star \star}$} & & {$[0,014]^{\star}$} & \\
\hline Régimen basado en el derecho inglés (país) & 31,556 & 55,616 & & \\
\hline Pequeñas empresas & {$[11,397]^{\star \star *}$} & {$[13,229]^{\star \star \star}$} & & \\
\hline Régimen basado en el derecho inglés (país) & 22,476 & 30,022 & & \\
\hline Empresas medianas & {$[7,154]^{\star \star \star}$} & {$[10,190]^{\star \star *}$} & & \\
\hline Derechos efectivos de los acreedores (país) & & & 23,826 & 44,053 \\
\hline Pequeñas empresas & & & {$[6,171]^{\star \star \star}$} & {$[9,157]^{\star \star \star}$} \\
\hline Derechos efectivos de los acreedores (país) & & & 17,629 & 30,435 \\
\hline Empresas medianas & & & {$[5,607]^{\star \star *}$} & {$[7,786]^{\star \star \star}$} \\
\hline Registro público o privado x régimen basado en el derecho inglés & & $-35,180$ & $-0,037$ & 0,000 \\
\hline Pequeñas empresas & & {$[17,419]^{* *}$} & & \\
\hline Registro público o privado x régimen basado en el derecho inglés & & $-10,944$ & & \\
\hline Empresas medianas & & {$[12,285]$} & & \\
\hline Cobertura de registro de crédito x régimen basado en el derecho inglés & $-0,051$ & & & \\
\hline Pequeñas empresas & {$[0,025]^{\star *}$} & & & \\
\hline Cobertura de registro de crédito x régimen basado en el derecho inglés & $-0,017$ & & & \\
\hline Empresas medianas & {$[0,019]$} & & & \\
\hline Registro público o privado $\mathrm{x}$ derechos efectivos de los acreedores & & & & $-26,367$ \\
\hline Pequeñas empresas & & & & {$[10,542]^{\star \star}$} \\
\hline Registro público o privado $\mathrm{x}$ derechos efectivos de los acreedores & & & & $-20,811$ \\
\hline Empresas medianas & & & & {$[9,425]^{\star *}$} \\
\hline Cobertura de registro de crédito $\mathrm{x}$ derechos efectivos de los acreedores & & & $-0,037$ & \\
\hline Pequeñas empresas & & & {$[0,018]^{\star *}$} & \\
\hline Cobertura de registro de crédito $\mathrm{x}$ derechos efectivos de los acreedores & & & $-0,020$ & \\
\hline Empresas medianas & & & {$[0,015]$} & \\
\hline
\end{tabular}


Cuadro 4 (conclusión)

\begin{tabular}{lccccc}
\hline $\begin{array}{l}\text { Variable dependiente: porcentaje de inversión financiado } \\
\text { con crédito bancario (nivel de empresa) }\end{array}$ & (1) & (2) & (3) & (4) \\
\hline Observaciones & 6604 & 6604 & 6604 & 6604 \\
\hline Efectos fijos del país & Sí & Sí & Sí & Sí \\
\hline Efectos fijos del sector & Sí & Sí & Sí & Sí \\
\hline Cantidad de países & 61 & 61 & 61 & 61 \\
\hline
\end{tabular}

Fuente: Banco Mundial, World Business Environment Survey (WBES) y S. Djankov, C. McLiesh and A. Shleifer, "Private credit in 129 countries", Journal of Financial Economics, vol. 84, № 2, Amsterdam, Elsevier, 2007.

Nota: Los errores estándar robustos se muestran entre paréntesis. Los agrupamientos son por tamaño de país. ${ }^{*}$ significativo al $10 \%$; ${ }^{\star \star}$ significativo al $5 \%$; ${ }^{\star \star \star}$ significativo al $1 \%$.

\section{Robustez}

Una posible causa de los resultados expuestos es que las mediciones utilizadas para captar el desarrollo de los organismos de información crediticia o la protección jurídica de los acreedores son variables sustitutas para el desarrollo económico. Es muy probable que los países más desarrollados tengan instituciones de información sobre solvencia crediticia más robustas y derechos efectivos de los acreedores más afianzados (gracias a un firme respeto del estado de derecho). Para enfrentar este posible sesgo, ajustamos por el desarrollo económico de dos maneras posibles: primero, usando variables ficticias que indican si un país es un país de ingresos bajos o de ingresos medios según la clasificación del Banco Mundial (columnas 1 a 4 del cuadro 5) y segundo, usando el PIB per cápita en virtud de la paridad del poder adquisitivo (PPA) (columnas 5 y 6). Como antes, se consideraron medidas del desarrollo de la información de crédito - la variable de cobertura máxima y la variable ficticia-, así como la medición de la protección jurídica de los acreedores. Cualitativamente, los resultados fueron los mismos. Si bien se registra una reducción en las estimaciones puntuales de la variable de cobertura máxima y la variable ficticia del registro de crédito, los resultados siguen apuntando en la misma dirección: los registros de crédito juegan un importante papel en la reducción de la brecha de financiamiento entre las pequeñas y las grandes empresas. No resulta sorprendente constatar que los derechos efectivos de los acreedores - las variables sustitutas para protección jurídica de los acreedores, que incluyen el estado de derecho- son más débiles cuando se incluyen ajustes por nivel de ingreso, pero, en la mayoría de las especificaciones, siguen siendo significativos. En el caso de los países basados en el derecho inglés, los resultados son los mismos que antes.

Cuadro 5

Resultados econométricos cuando se ajusta por el nivel de ingreso

\begin{tabular}{|c|c|c|c|c|c|c|c|}
\hline $\begin{array}{l}\text { Variable dependiente: porcentaje } \\
\text { de inversión financiado con crédito } \\
\text { bancario (nivel de empresa) }\end{array}$ & (1) & (2) & (3) & (4) & (5) & (6) & (7) \\
\hline \multirow{2}{*}{ Empresas exportadoras } & 9,627 & 9,959 & 9,536 & 9,956 & 9,707 & 9,635 & 10,139 \\
\hline & {$[2,344]^{\star \star \star}$} & {$[2,349]^{\star \star \star}$} & {$[2,340]^{\star \star \star}$} & {$[2,355]^{\star \star \star}$} & {$[2,337]^{\star \star \star}$} & {$[2,324]^{\star \star \star}$} & {$[2,344]^{\star \star \star}$} \\
\hline \multirow{2}{*}{ Propiedad estatal (empresa) } & $-7,036$ & $-5,403$ & $-6,210$ & $-5,067$ & $-6,517$ & $-5,964$ & $-5,150$ \\
\hline & {$[4,238]^{*}$} & {$[4,209]$} & {$[4,234]$} & {$[4,208]$} & {$[4,239]$} & {$[4,230]$} & {$[4,220]$} \\
\hline \multirow{2}{*}{ Propiedad de capitales extranjeros (empresa) } & 0,256 & 0,004 & $-0,026$ & $-0,280$ & $-0,223$ & $-0,283$ & $-0,434$ \\
\hline & {$[3,108]$} & {$[3,108]$} & {$[3,097]$} & {$[3,117]$} & {$[3,086]$} & {$[3,088]$} & {$[3,092]$} \\
\hline \multirow{2}{*}{ Pequeñas empresas } & $-35,353$ & $-22,886$ & $-34,358$ & $-23,535$ & $-62,474$ & $-56,641$ & $-45,276$ \\
\hline & {$[11,982]^{\star \star \star}$} & {$[10,704]^{\star *}$} & {$[13,548]^{\star \star}$} & {$[13,637]^{*}$} & {$[9,231]^{\star \star \star}$} & {$[8,552]^{\star * *}$} & {$[4,992]^{\star \star \star}$} \\
\hline \multirow{2}{*}{ Empresas medianas } & $-24,777$ & $-17,529$ & $-31,952$ & $-24,138$ & $-31,139$ & $-27,550$ & $-21,946$ \\
\hline & {$[9,415]^{\star \star \star}$} & {$[10,071]^{\star}$} & {$[11,696]^{\star \star \star}$} & {$[12,675]^{\star}$} & {$[6,692]^{\star \star \star}$} & {$[6,195]^{\star \star \star}$} & {$[4,010]^{\star \star \star}$} \\
\hline
\end{tabular}




\begin{tabular}{|c|c|c|c|c|c|c|c|}
\hline $\begin{array}{l}\text { Variable dependiente: porcentaje } \\
\text { de inversión financiado con crédito } \\
\text { bancario (nivel de empresa) }\end{array}$ & (1) & (2) & (3) & (4) & (5) & (6) & (7) \\
\hline Registro público o privado & 29,737 & & 28,967 & & 31,678 & 31,142 & \\
\hline Pequeña empresa & {$[8,904]^{\star \star \star}$} & & {$[8,706]^{\star \star \star}$} & & {$[9,075]^{\star \star \star}$} & {$[8,830]^{\star \star \star}$} & \\
\hline Registro público o privado & 14,864 & & 15,564 & & 14,716 & 15,452 & \\
\hline Empresas medianas & {$[6,755]^{\star *}$} & & {$[6,791]^{\star *}$} & & {$[6,768]^{\star *}$} & {$[6,750]^{\star *}$} & \\
\hline Cobertura del registro de crédito & & 0,036 & & 0,043 & & & 0,044 \\
\hline Pequeñas empresas & & {$[0,014]^{\star *}$} & & {$[0,015]^{\star \star \star}$} & & & {$[0,015]^{\star \star \star}$} \\
\hline Cobertura del registro de crédito & & 0,015 & & 0,019 & & & 0,010 \\
\hline Empresas medianas & & {$[0,013]$} & & {$[0,013]$} & & & {$[0,013]$} \\
\hline Régimen basado en el derecho inglés (país) & 29,137 & 22,942 & & & 28,716 & & 20,642 \\
\hline Pequeñas empresas & {$[8,062]^{\star \star *}$} & {$[7,375]^{\star \star \star}$} & & & {$[8,582]^{\star \star \star}$} & & {$[7,238]^{\star \star \star}$} \\
\hline Régimen basado en el derecho inglés (país) & 23,359 & 21,660 & & & 21,671 & & 19,827 \\
\hline Empresas medianas & {$[5,958]^{\star \star \star}$} & {$[6,252]^{\star \star \star}$} & & & {$[5,616]^{\star \star \star}$} & & {$[5,557]^{\star \star \star}$} \\
\hline Derechos efectivos de los acreedores (país) & & & 13,902 & 8,297 & & 19,634 & \\
\hline Pequeñas empresas & & & {$[7,172]^{*}$} & {$[7,116]$} & & {$[8,328]^{\star \star}$} & \\
\hline Derechos efectivos de los acreedores (país) & & & 19,508 & 16,569 & & 19,088 & \\
\hline Empresas medianas & & & {$[6,943]^{\star \star \star}$} & {$[6,734]^{\star *}$} & & {$[7,222]^{\star \star \star}$} & \\
\hline Bajos ingresos (país) & $-47,813$ & $-44,401$ & $-34,878$ & $-34,416$ & & & \\
\hline Pequeñas empresas & {$[11,840]^{\star * *}$} & {$[13,013]^{\star \star \star}$} & {$[16,606]^{\star *}$} & {$[17,690]^{*}$} & & & \\
\hline Bajos ingresos (país) & $-14,649$ & $-14,271$ & 6,737 & 5,266 & & & \\
\hline Empresas medianas & {$[8,295]^{*}$} & {$[10,927]$} & {$[13,954]$} & {$[15,965]$} & & & \\
\hline Ingresos medios (país) & $-23,197$ & $-17,893$ & $-20,339$ & $-15,815$ & & & \\
\hline Pequeñas empresas & {$[7,859]^{\star \star \star}$} & {$[9,106]^{\star \star}$} & {$[10,496]^{\star}$} & {$[12,288]$} & & & \\
\hline Ingresos medios (país) & $-4,600$ & $-2,620$ & 4,544 & 5,679 & & & \\
\hline Empresas medianas & {$[7,110]$} & {$[8,569]$} & {$[9,690]$} & {$[11,266]$} & & & \\
\hline Ln per cápita PIB (país) & & & & & 12,670 & 6,009 & 10,659 \\
\hline Pequeñas empresas & & & & & {$[3,841]^{\star \star \star}$} & {$[5,984]$} & {$[4,113]^{\star \star \star}$} \\
\hline Ln per cápita PIB (país) & & & & & 5,381 & $-1,660$ & 5,826 \\
\hline Empresas medianas & & & & & {$[2,872]^{*}$} & {$[4,909]$} & {$[3,700]$} \\
\hline Observaciones & 6604 & 6604 & 6604 & 6604 & 6604 & 6604 & 6604 \\
\hline Efectos fijos del país & Sí & Sí & Sí & Sí & Sí & Sí & Sí \\
\hline Efectos fijos del sector & Sí & Sí & Sí & Sí & Sí & Sí & Sí \\
\hline Cantidad de países & 61 & 61 & 61 & 61 & 61 & 61 & 61 \\
\hline
\end{tabular}

Fuente: Banco Mundial, World Business Environment Survey (WBES) y S. Djankov, C. McLiesh y A. Shleifer, "Private credit in 129 countries", Journal of Financial Economics, vol. 84, № 2, Amsterdam, Elsevier, 2007.

Nota: Los errores estándar robustos se muestran entre paréntesis. Los agrupamientos son por tamaño de país. * significativo al 10\%; ** significativo al 5\%; ${ }^{* \star *}$ significativo al 1\%; Ln: Logaritmo natural.

En el cuadro 6 se presentan las estimaciones para el intercambio de información y la protección jurídica de los acreedores usando la especificación de la columna 2 del cuadro 3, pero excluyendo un país de la muestra a la vez. En todos los casos, nuestros principales coeficientes estimados son positivos y significativos a intervalos de confianza convencionales. 


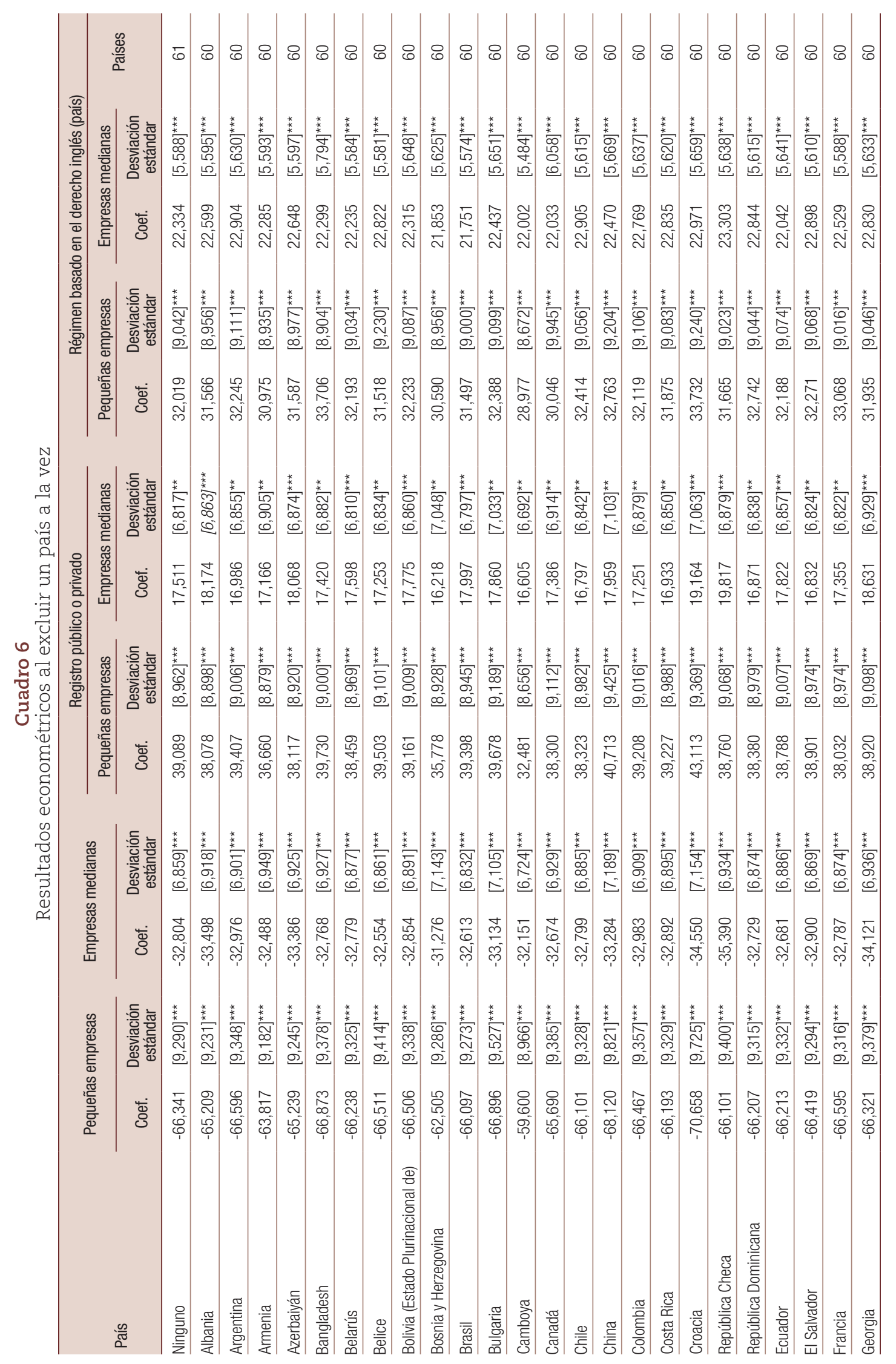




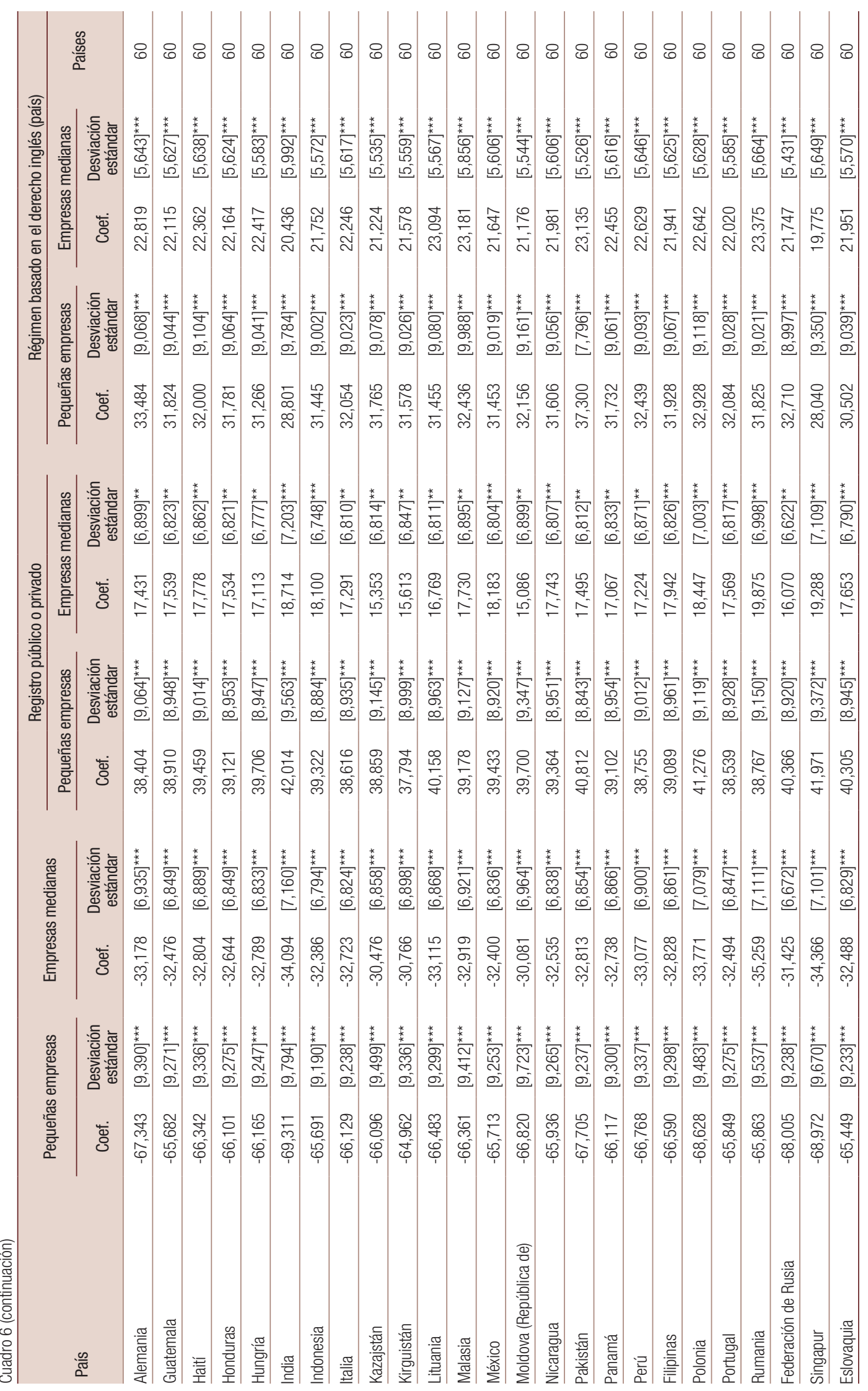




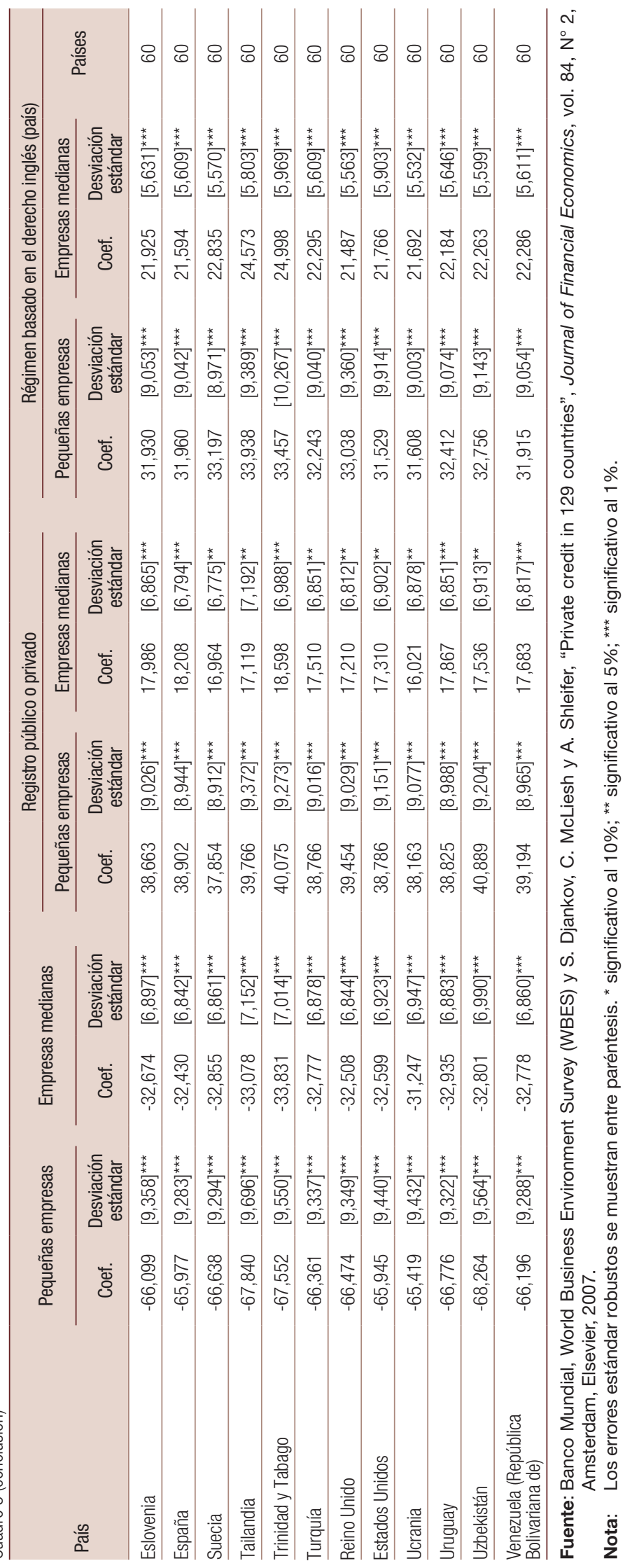




\section{Comentarios finales}

Sobre la base de una muestra de 61 países, en este estudio se ofrece evidencia empírica sobre la importancia de la protección de los acreedores y el desarrollo de mecanismos de intercambio de información para permitir que empresas de diferente tamaño puedan acceder a créditos bancarios. Se utilizaron técnicas de variable dependiente limitada para analizar si el desarrollo de instituciones de intercambio de información -como los organismos privados de información crediticia o los registros públicos de crédito - ayuda a reducir la brecha de financiamiento entre las grandes empresas y las pymes. Además, se recurrió al uso de variables ficticias por país, como mecanismo de control frente a posibles casos de omisión de alguno de ellos, lo que ha sido uno de los grandes problemas en los anteriores estudios sobre el tema.

Los resultados indican que mejorar la cobertura de los organismos privados de información crediticia y los registros públicos de crédito tiene un efecto estadísticamente significativo en la reducción de la brecha entre el porcentaje de inversión financiada con crédito bancario para las grandes empresas y las pequeñas empresas. Los resultados obtenidos en este estudio no solo son estadísticamente significativos, sino que también son importantes desde el punto de vista económico. El aumento de una desviación estándar en la cobertura de los organismos de información crediticia reduce ocho puntos porcentuales la brecha de financiamiento entre las pequeñas y las grandes empresas. Usando la misma técnica, también se investigó si la protección de los acreedores, medida por los derechos efectivos de los acreedores y el tipo de sistema jurídico, reduce la brecha entre el crédito bancario para las grandes y las pequeñas empresas. En los países basados en el derecho inglés, que se caracterizan por un elevado nivel de protección de los acreedores, esta brecha es entre 20 y 30 puntos porcentuales menor que en otros países. Una mejora de los derechos efectivos de los acreedores de una desviación estándar reduce entre 9 y 14 puntos porcentuales la brecha entre las pequeñas y las grandes empresas.

El principal promotor de políticas para la reducción de la brecha de financiamiento es una mejora en la protección de los derechos de los acreedores. No obstante, especialmente en el caso de las pequeñas empresas, los esfuerzos dirigidos a fortalecer los derechos de los acreedores - lo que constituye una tarea titánica que supone amplias reformas - pueden reforzarse con el desarrollo de mecanismos de intercambio de información. Nuestros resultados indican que la recompensa de este último tipo de esfuerzo será más grande en los países donde los derechos de los acreedores no están tan protegidos. Sería conveniente que en los futuros trabajos teóricos y empíricos se estudiara la complementariedad del intercambio de información y los derechos de propiedad de los acreedores que se refleja en nuestros resultados. Otra interesante vía de investigación sería centrarse en el efecto del intercambio de información sobre la competencia y viceversa, y en el impacto de esta interacción en el acceso de las pymes al crédito ${ }^{23}$. Como se muestra en este estudio, el intercambio de información reduce las asimetrías de información entre prestamistas y acreedores, pero también puede reducir la capacidad del banco de apropiarse de las rentas de las pymes. Si bien esto puede incrementar los beneficios de estas empresas, como lo afirman Petersen y Rajan (1994), también puede hacer que los bancos estén menos dispuestos a prestar a las pymes, lo que reduce su acceso al crédito.

${ }^{23}$ Brown y Zehnder (2010) analizan la interacción entre el poder de mercado y el intercambio de información. 


\section{Bibliografía}

Barron, J. y M. Staten (2003), "The value of comprehensive credit reports: lessons from the U.S. experience", Credit Reporting Systems and the International Economy, M.J. Miller (ed.), Cambridge, Massachusetts, The MIT Press.

Beck, T. y A. Demirgüç-Kunt (2006), "Small and medium-size enterprises: access to finance as a growth constraint", Journal of Banking and Finance, vol. 30, № 11, Amsterdam, Elsevier.

Beck, T., A. Demirgüç-Kunt y M. Martínez Pería (2008), "Banking financing for SMEs around the world: drivers, obstacles, business models and lending practices", Policy Research Working Paper, $N^{\circ} 4785$, Washington, D.C., Banco Mundial.

Beck, T., A. Demirgüç-Kunt y V. Maksimovic (2005), "Financial and legal constraints to growth: does firm size matter?", The Journal of Finance, vol. 60, No 1, Wiley.

(2001), "Financing patterns across the world: the role of institutions", Policy Research Working Paper, $N^{\circ} 2905$, Washington, D.C., Banco Mundial.

Beck, T. y otros (2006), "The determinants of financing obstacles", Journal of International Money and Finance, vol. 25, № 6, Amsterdam, Elsevier.

Bennardo, A., M. Pagano y S. Piccolo (2009), "Multiple-bank lending, creditor rights and information sharing", CEPR Discussion Papers, № 7186, Londres, Centro de Investigación sobre Políticas Económicas.

BID (Banco Interamericano de Desarrollo) (2004), Desencadenar el crédito: cómo ampliar y estabilizar la banca, Washington, D.C.

Brown, M., T. Jappelli y M. Pagano (2009), "Information sharing and credit: firm-level evidence from transition countries", Journal of Financial Intermediation, vol. 18, № 2, Amsterdam, Elsevier.

Brown, M. y C. Zehnder (2010), "The emergence of information sharing in credit markets", Journal of Financial Intermediation, vol. 19, № 2, Amsterdam, Elsevier.

Djankov, S., C. McLiesh y A. Shleifer (2007), "Private credit in 129 countries", Journal of Financial Economics, vol. 84, № 2, Amsterdam, Elsevier.

Feldmann, H. (2013), "Financial system sophistication and unemployment in industrial countries", International Journal of Finance and Economics, vol. 18, № 4, Wiley.

Freixas, X. y J. Rochet (2008), Microeconomics of Banking, Cambridge, Massachusetts, The MIT Press.

Galindo, A. y A. Micco (2007), "Creditor protection and credit response to shocks", World Bank Economic Review, vol. 21, № 3, Washington, D.C., Banco Mundial.

(2005), "Bank credit to small and medium-sized enterprises: the role of creditor protection", Documento de Trabajo, No 347, Santiago, Banco Central de Chile.

Galindo, A. y M. Miller (2001), "Can Credit Registries Reduce Credit Constraints? Empirical Evidence on the Role of Credit Registries in Firm's Investment Decisions", Washington, D.C., Banco Interamericano de Desarrollo, inédito.

Greene, W. (2004), "Fixed effects and bias due to the incidental parameters problem in the Tobit model", Econometric Reviews, vol. 23, № 2, Taylor \& Francis.

(2002), "The bias of the fixed effects estimator in nonlinear models", Universidad de Nueva York [en línea] http://people.stern.nyu.edu/wgreene/nonlinearfixedeffects.pdf.

Jappelli, T. y M. Pagano (2002), "Information sharing, lending and defaults: cross-country evidence", Journal of Banking \& Finance, vol. 26, № 10, Amsterdam, Elsevier.

Judson, R. y A. Owen (1996), "Estimating Dynamic Panel Data Models: A Practical Guide for Macroeconomists" [en línea] https://www.federalreserve.gov/pubs/feds/1997/199703/199703pap.pdf.

Kallberg, J. y G. Udell (2003), "Private business information exchange in the United States", Credit Reporting Systems and the International Economy, M.J. Miller (ed.), Cambridge, Massachusetts, The MIT Press.

Kaufmann, D., A. Kraay y M. Mastruzzi (2009), "Governance matters VIII: aggregate and individual governance indicators, 1996-2008", Policy Research Working Paper, № 4978, Washington, D.C., Banco Mundial.

La Porta, R. y otros (1998), "Law and finance", Journal of Political Economy, vol. 106, № 6, Chicago, The University of Chicago Press. (1997), "Legal determinants of external finance", Journal of Finance, vol. 52, № 93, Wiley.

Love, I. y N. Mylenko (2003), "Credit reporting and financial constraints", Policy Research Working Paper, $N^{\circ}$ 3142, Washington, D.C., Banco Mundial.

Moulton, B. (1990), "An illustration of a pitfall in estimating the effects of aggregate variables on micro units", The Review of Economics and Statistics, vol. 72, № 2, Cambridge, Massachusetts, The MIT Press. 
Padilla, A.J. y M. Pagano (1997), "Endogenous communication among lenders and entrepreneural incentives", The Review of Financial Studies, vol. 10, № 1, Oxford University Press.

Pagano, M. y T. Jappelli (1993), "Information sharing in credit markets", The Journal of Finance, vol. 48, $N^{\circ} 5$, Wiley.

Petersen, M. y R. Rajan (1994), "The benefits of lending relationships: evidence from small business data", The Journal of Finance, vol. 49, № 1, Wiley.

Powell, A. y otros (2004), "Improving credit information, bank regulation, and supervision: on the role and design of public credit registries", Policy Research Working Paper, № 3443, Washington, D.C., Banco Mundial.

Schiantarelli, F. (1996), "Financial constraints and investment: methodological issues and international evidence", Oxford Review of Economic Policy, vol. 12, № 2.

Schiffer, M. y B. Weder (2001), "Firm size and the business environment: worldwide survey results", Discussion Paper, № 43, Washington, D.C., Corporación Financiera Internacional.

Stiglitz, J.E. y A. Weiss (1981), "Credit rationing in markets with imperfect information", American Economic Review, vol. 71, № 3, Nashville, Tennessee, American Economic Association.

Townsend, R. (1979), "Optimal contracts and competitive markets with costly state verification", Journal of Economic Theory, vol. 21, № 2, Amsterdam, Elsevier.

Warnock, V. y F. Warnock (2008), "Markets and housing finance", Journal of Housing Economics, vol. 17, $N^{\circ} 3$, Amsterdam, Elsevier. 


\section{Anexo A1}

Cuadro A1.1

Datos por país

\begin{tabular}{|c|c|c|c|c|c|c|c|}
\hline & $\begin{array}{l}\text { Porcentaje } \\
\text { medio de } \\
\text { la inversión } \\
\text { financiado } \\
\text { con crédito } \\
\text { bancario }\end{array}$ & $\begin{array}{c}\text { Variable } \\
\text { ficticia de } \\
\text { institución } \\
\text { pública } 0 \\
\text { privada de } \\
\text { información } \\
\text { crediticia }\end{array}$ & $\begin{array}{l}\text { Cobertura } \\
\text { de registro } \\
\text { público de } \\
\text { crédito } \\
\text { (cada } \\
1.000 \text { ) }\end{array}$ & $\begin{array}{c}\text { Cobertura } \\
\text { de registro } \\
\text { privado de } \\
\text { crédito } \\
\text { (cada } \\
1.000 \text { ) }\end{array}$ & $\begin{array}{l}\text { Régimen } \\
\text { basado en } \\
\text { el derecho } \\
\text { inglés }\end{array}$ & $\begin{array}{l}\text { Índice de } \\
\text { derechos } \\
\text { efectivos } \\
\text { de los } \\
\text { acreedores }\end{array}$ & $\begin{array}{c}\text { PIB } \\
\text { per cápita, } \\
\text { ajustado } \\
\text { por PPA } \\
\text { (en } \\
\text { logaritmos) }\end{array}$ \\
\hline Albania & 3 & 0 & 0 & 0 & 0 & $-0,62$ & 8,39 \\
\hline Argentina & 30 & 1 & 149 & 475 & 0 & $-0,01$ & 9,25 \\
\hline Armenia & 3 & 0 & 0 & 0 & 0 & $-0,25$ & 7,69 \\
\hline Azerbaiyán & 2 & 0 & 0 & 0 & 0 & $-0,73$ & 7,74 \\
\hline Bangladesh & 13 & 1 & 1 & 0 & 1 & $-0,39$ & 6,76 \\
\hline Belarús & 5 & 1 & 0 & 0 & 0 & $-0,59$ & 8,61 \\
\hline Belice & 32 & 0 & 0 & 0 & 1 & 0,16 & 8,56 \\
\hline Bolivia (Estado Plurinacional de) & 24 & 1 & 55 & 134 & 0 & $-0,3$ & 8,13 \\
\hline Bosnia y Herzegovina & 16 & 0 & 0 & 0 & 0 & $-0,61$ & 8,47 \\
\hline Brasil & 26 & 1 & 44 & 439 & 0 & $-0,06$ & 8,97 \\
\hline Bulgaria & 6 & 0 & 0 & 0 & 0 & $-0,03$ & 8,78 \\
\hline Camboya & 7 & 0 & 0 & 0 & 0 & $-0,46$ & 6,85 \\
\hline Canadá & 21 & 1 & 0 & 806 & 1 & 0,53 & 10,34 \\
\hline Chile & 38 & 1 & 209 & 227 & 0 & 0,71 & 9,25 \\
\hline China & 9 & 0 & 0 & 0 & 0 & $-0,18$ & 7,82 \\
\hline Colombia & 29 & 1 & 0 & 187 & 0 & 0 & 8,79 \\
\hline Costa Rica & 18 & 1 & 7 & 55 & 0 & 0,21 & 8,97 \\
\hline Croacia & 19 & 0 & 0 & 0 & 0 & $-0,07$ & 9,39 \\
\hline República Checa & 10 & 0 & 0 & 0 & 0 & 0,53 & 9,71 \\
\hline República Dominicana & 26 & 1 & 0 & 423 & 0 & $-0,17$ & 8,6 \\
\hline Ecuador & 15 & 1 & 82 & 0 & 0 & 0 & 8,64 \\
\hline El Salvador & 28 & 1 & 130 & 128 & 0 & $-0,32$ & 8,53 \\
\hline Francia & 11 & 1 & 12 & 0 & 0 & 0 & 10,25 \\
\hline Georgia & 7 & 0 & 0 & 0 & 0 & $-0,47$ & 7,73 \\
\hline Alemania & 17 & 1 & 5 & 693 & 0 & 1,55 & 10,3 \\
\hline Guatemala & 27 & 1 & 0 & 35 & 0 & $-0,21$ & 8,27 \\
\hline Haití & 11 & 1 & 1 & 0 & 0 & $-0,77$ & 7,08 \\
\hline Honduras & 20 & 1 & 45 & 0 & 0 & $-0,43$ & 7,97 \\
\hline Hungría & 15 & 1 & 0 & 15 & 0 & 0,22 & 9,47 \\
\hline India & 33 & 0 & 0 & 0 & 1 & 0,06 & 7,41 \\
\hline Indonesia & 15 & 1 & 3 & 0 & 0 & $-0,44$ & 7,92 \\
\hline Italia & 42 & 1 & 55 & 416 & 0 & 0,51 & 10,2 \\
\hline Kazajstán & 7 & 0 & 0 & 0 & 0 & $-0,67$ & 8,55 \\
\hline Kirguistán & 1 & 0 & 0 & 0 & 0 & $-0,63$ & 7,29 \\
\hline Lituania & 8 & 1 & 7 & 0 & 0 & 0,1 & 9,14 \\
\hline Malasia & 17 & 1 & 105 & 461 & 1 & 0,57 & 9,2 \\
\hline México & 11 & 1 & 0 & 382 & 0 & 0 & 9,35 \\
\hline Moldova (República de) & 7 & 0 & 0 & 0 & 0 & $-0,2$ & 7,31 \\
\hline
\end{tabular}


Cuadro A1.1 (conclusión)

\begin{tabular}{|c|c|c|c|c|c|c|c|}
\hline & $\begin{array}{l}\text { Porcentaje } \\
\text { medio de } \\
\text { la inversión } \\
\text { financiado } \\
\text { con crédito } \\
\text { bancario }\end{array}$ & $\begin{array}{l}\text { Variable } \\
\text { ficticia de } \\
\text { institución } \\
\text { pública o } \\
\text { privada de } \\
\text { información } \\
\text { crediticia }\end{array}$ & $\begin{array}{l}\text { Cobertura } \\
\text { de registro } \\
\text { público de } \\
\text { crédito } \\
\text { (cada } \\
1.000 \text { ) }\end{array}$ & $\begin{array}{l}\text { Cobertura } \\
\text { de registro } \\
\text { privado de } \\
\text { crédito } \\
\text { (cada } \\
1.000 \text { ) }\end{array}$ & $\begin{array}{l}\text { Régimen } \\
\text { basado en } \\
\text { el derecho } \\
\text { inglés }\end{array}$ & $\begin{array}{l}\text { Índice de } \\
\text { derechos } \\
\text { efectivos } \\
\text { de los } \\
\text { acreedores }\end{array}$ & $\begin{array}{c}\text { PIB } \\
\text { per cápita, } \\
\text { ajustado } \\
\text { por PPA } \\
\text { (en } \\
\text { logaritmos) }\end{array}$ \\
\hline Nicaragua & 17 & 1 & 50 & 0 & 0 & $-0,86$ & 7,62 \\
\hline Pakistán & 27 & 1 & 1 & 0 & 1 & $-0,17$ & 7,55 \\
\hline Panamá & 44 & 1 & 0 & 302 & 0 & 0,04 & 8,98 \\
\hline Perú & 25 & 1 & 92 & 185 & 0 & 0 & 8,61 \\
\hline Filipinas & 19 & 1 & 0 & 22 & 0 & $-0,08$ & 7,84 \\
\hline Polonia & 13 & 0 & 0 & 0 & 0 & 0,16 & 9,32 \\
\hline Portugal & 13 & 1 & 496 & 24 & 0 & 0,35 & 9,89 \\
\hline Rumania & 10 & 0 & 0 & 0 & 0 & $-0,13$ & 8,85 \\
\hline Federación de Rusia & 6 & 0 & 0 & 0 & 0 & $-0,23$ & 9 \\
\hline Singapur & 23 & 0 & 0 & 0 & 1 & 1,71 & 10,46 \\
\hline Eslovaquia & 11 & 1 & 2 & 0 & 0 & 0,13 & 9,44 \\
\hline Eslovenia & 17 & 1 & 14 & 0 & 0 & 0,7 & 9,84 \\
\hline España & 20 & 1 & 305 & 48 & 0 & 0,71 & 10,09 \\
\hline Suecia & 19 & 1 & 0 & 489 & 0 & 0,55 & 10,23 \\
\hline Tailandia & 34 & 0 & 0 & 0 & 1 & 0,21 & 8,56 \\
\hline Trinidad y Tabago & 37 & 1 & 315 & 0 & 1 & 0,11 & 9,42 \\
\hline Turquía & 20 & 1 & 7 & 0 & 0 & 0,03 & 9,12 \\
\hline Reino Unido & 11 & 1 & 0 & 652 & 1 & 2,14 & 10,25 \\
\hline Estados Unidos & 18 & 1 & 0 & 810 & 1 & 0,49 & 10,54 \\
\hline Ucrania & 6 & 0 & 0 & 0 & 0 & $-0,42$ & 8,2 \\
\hline Uruguay & 32 & 1 & 49 & 479 & 0 & 0,32 & 9,14 \\
\hline Uzbekistán & 5 & 0 & 0 & 0 & 0 & $-0,59$ & 7,37 \\
\hline Venezuela (República Bolivariana de) & 15 & 1 & 97 & 0 & 0 & $-0,67$ & 9,19 \\
\hline
\end{tabular}

Fuente: Elaboración propia, sobre la base de Banco Mundial, World Business Environment Survey (WBES) y S. Djankov, C. McLiesh y A. Shleifer, "Private credit in 129 countries", Journal of Financial Economics, vol. 84, N 2, Amsterdam, Elsevier, 2007. 